\title{
Comparative Study of Microstrip Patch Antenna for Different Feed Line and Different Substrate
}

\author{
Harish Langar, Atul Shire
}

Assistant Professor, Jawaharlal Darda Institute of Engineering and Technology, Yavatmal, Maharashtra, India

\begin{abstract}
This paper describes different feeding technique and different substrate applicable to Microstrip patch antenna which is one of the important aspects. A good impedance matching condition between the line and patch without any additional matching elements depends on feeding techniques used and substrate used. After analysis various feeding techniques for different substrate, this paper gives a better understanding of the design parameters of an antenna and their effect on Impedance, VSWR, bandwidth and gain. Finally, simulation is done using design software HFSS.
\end{abstract}

Keywords : Microstrip Patch Antenna, Impedance, Bandwidth, VSWR, HFSS, Gain.

\section{INTRODUCTION}

Microstrip patch antennas have number of advantages such as low profile, easy to fabricate and conformability to mounting hosts also size, return loss reduction and bandwidth enhancement and impedance matching are major design considerations for practical applications of microstrip antennas.The lightweight construction and the suitability for integration with microwave integrated circuits are of their advantages.

A comparison between various feeding techniques for different substrate has been done. Finally, a microstrip patch antenna at specific frequency i.e. $2.40 \mathrm{GHz}$ has been designed and, simulated on the design software HFSS.

\section{MICROSTRIP PATCH ANTENNA}

Microstrip antenna consists of very small conducting patch which is built on a ground plane separated by dielectric substrate like RT Duroid etc. The patch is generally made of conducting material like copper or gold and that can be any possible shape [1]. The radiating patch and the feed lines are usually photo etched on the dielectric substrate. The conducting patch, theoretically, can be possible to design of any shape, In general rectangular and circular configurations are the most commonly used $[1,5]$. Some of the other configurations used are complex to analyze and require large numerical computations.In its most fundamental form,a microstrip patch antenna consist of a radiating patch on one side of a dielectric substrate which has ground plane on the other side [1] is illustrated in fig 1.

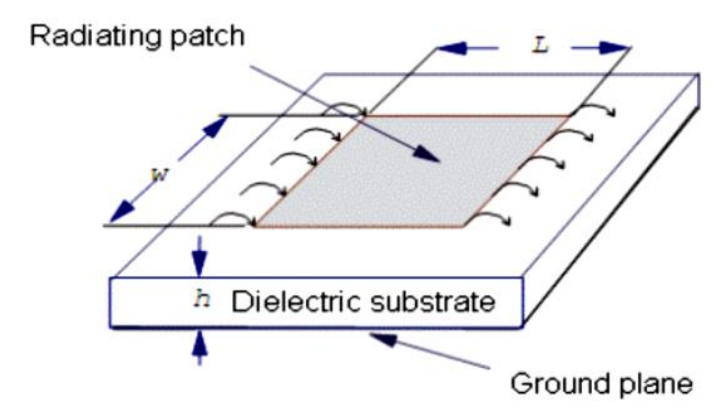

Figure 1: Structure of Microstrip Patch Antenna 


\section{DIFFERENT FEEDING TECHNIQUES}

Microstrip patch antennas can be fed by a number of techniques [1]. These techniques deliver the $\mathrm{RF}$ power is directly fed to the radiating patch using a connecting element such as a microstrip line. The Two most popular feed techniques used are the microstrip line, coaxial probe.

\section{A . Microstrip Line Feed}

Microstrip feed technique; a conducting strip is made contact directly to the edge of the radiating patch or Microstrip patch. The conducting strip is having minimum in width as compared to the patch and Microstrip feed technique has the advantage that the feed can be etched on the same substrate to provide a planar structure [5, 6].It is an easy feeding Technique, since it provides ease of fabrication and simplicity in modelling as well as impedance matching. According to the thickness of the dielectric substrate being used, increases, surface waves and spurious feed radiation also increases, that can affect the bandwidth of the antenna [6].

\section{B. Coaxial Probe Feed}

The Coaxial feed or probe feed is a very common or popular technique used for feeding Microstrip patch antennas. The inner conductor of the coaxial connector extends through the dielectric and is soldered to the radiating patch; the outer conductor is connected to the ground plane. The good advantage of this type of feeding technique is that the feed can be placed at any desired location inside the patch to perfect match with its input impedance. Also, the main disadvantage is that it provides narrow bandwidth and is difficult to model since a hole has to be drilled in the substrate and the connector protrudes outside the ground plane, thus not making it completely planar for thick substrates. Also, for thicker substrates, the increased probe length makes the input impedance more inductive, leading to matching problems. It is seen above that for a thick dielectric substrate, which provides broad bandwidth.

\section{DIFFERENT SUBSTRTE}

For Microstrip patch antenna consists the patch which is mounted on the material that material is known as substrate which having the dielectric constant and loss tangent. The Four materials are used to design the Microstrip patch antenna for comparison of parameter.
a) FR4
b) Rogers RO33054
c) Taconic TLE
d) RT Duriod

\section{DESIGN CONSIDERATIONS}

Microstrip patch antenna consists of very thin metallic strip (patch) placed on ground plane where the thickness of the metallic strip is restricted by $\mathrm{t}<<$ $\lambda 0$ and the height is restricted by $0.0003 \lambda 0 \leq h \leq$ $.05 \lambda 0$. The Microstrip patch is designed so that its radiation pattern maximum is normal to the patch. For a rectangular patch, the length $L$ of the element is usually $\lambda 0 / 3<\mathrm{L}<\lambda 0 / 2[1,6]$.

\section{A. Procedure for Microstrip Patch Antenna}

The Performance of the microstrip patch antenna depends on its resonant frequency, dimension. Depending on the dimension, the operating frequency, radiation efficiency, directivity, return loss are influenced. For an efficient radiation, Calculation of Geometrical Dimensions For the calculation of geometrical dimensions of the microstrip patch the fact that the electrical dimensions are larger than geometrical dimensions should be taken into 
consideration. This is caused by the existence of fringing field beyond the limit, given by the geometrical dimensions of the microstrip patch.

(a) Calculated patch width

$$
W=\frac{c}{2 f_{0}} \sqrt{\frac{2}{\varepsilon_{r}+1}}
$$

(b) Calculated effective dielectric constant

$$
\varepsilon_{\text {reff }}=\frac{\varepsilon_{r}+1}{2}+\frac{\varepsilon_{r}-1}{2}\left[1+12 \frac{h}{W}\right]^{-1 / 2}
$$

(c) Calculated the extended incremental length

' $\Delta L$ 'of the patch due to fringing effect

$$
\Delta L=0.412 h \frac{\left(\varepsilon_{\text {reff }}+0.3\right)\left[\frac{W}{h}+0.264\right]}{\left(\varepsilon_{\text {reff }}+0.258\right)\left[\frac{W}{h}+0.8\right]}
$$

(d) Calculated the patch effective length Leff

$$
L_{e f f}=\frac{c}{2 f_{0} \sqrt{\varepsilon_{\text {reff }}}}
$$

(e) Calculated the patch actual length

$$
L=L_{\text {eff }}-2 \Delta L
$$

(f) Calculated Wavelength

$$
\lambda_{0}=\frac{c}{f_{0}}
$$

(g) Calculation of the ground plane dimensions for single patch (Lg and $\mathrm{Wg})$ :

$$
\mathrm{Lg}=6 \mathrm{~h}+\mathrm{L} \text { and } \mathrm{Wg}=6 \mathrm{~h}+\mathrm{W}
$$

FR4 as the substrate with dielectric constant of 4.4. The rest of the basic parameters are: Resonant Frequency: fo $=2.4 \mathrm{GHz}$,Substrate Permittivity: $\varepsilon \mathrm{r}=$ 4.4 (FR4),Substrate Thickness: $\mathrm{h}=1.6 \mathrm{~mm}$,Loss tangent: $\tan \delta=0.002$

ROGERS RO4350 as the substrate with dielectric constant of 3.66. The rest of the basic parameters are: Resonant Frequency: fo $=2.4 \mathrm{GHz}$,Substrate Permittivity: $\varepsilon r=3.66$ (ROGERS RO4350), Substrate Thickness: $\mathrm{h}=1.6 \mathrm{~mm}$,Loss tangent: $\tan \delta=0.004$
TACONIC TLE as the substrate with dielectric constant of 2.95. The rest of the basic parameters are:Resonant Frequency: fo $=2.4 \mathrm{GHz}$,Substrate Permittivity: $\varepsilon r=2.95$ (TACONIC TLE),Substrate Thickness: $\mathrm{h}=1.6 \mathrm{~mm}$,Loss tangent: $\tan \delta=0.0028$ RT Duroid as the substrate with dielectric constant of 2.2. The rest of the basic parameters are:Resonant Frequency: fo $=2.4 \mathrm{GHz}$,Substrate Permittivity: $\varepsilon \mathrm{r}=$ 2.2 (RT Duroid),Substrate Thickness: $\mathrm{h}=1.6 \mathrm{~mm}$,Loss tangent: $\tan \delta=0.0009$ from this calculation Microstrip patch antenna design in hfss software for two feed line and four substrate.

\section{DESIGNING}

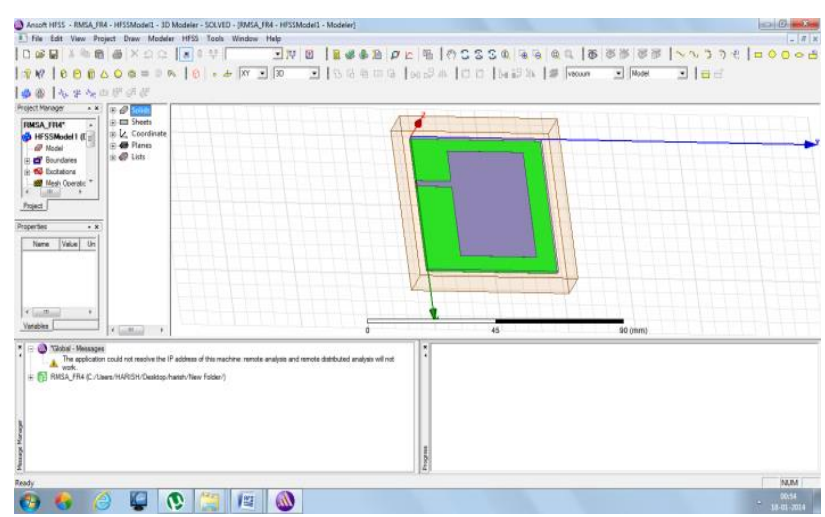

Figure 2 : RMSA Design of FR4 for microstrip feed

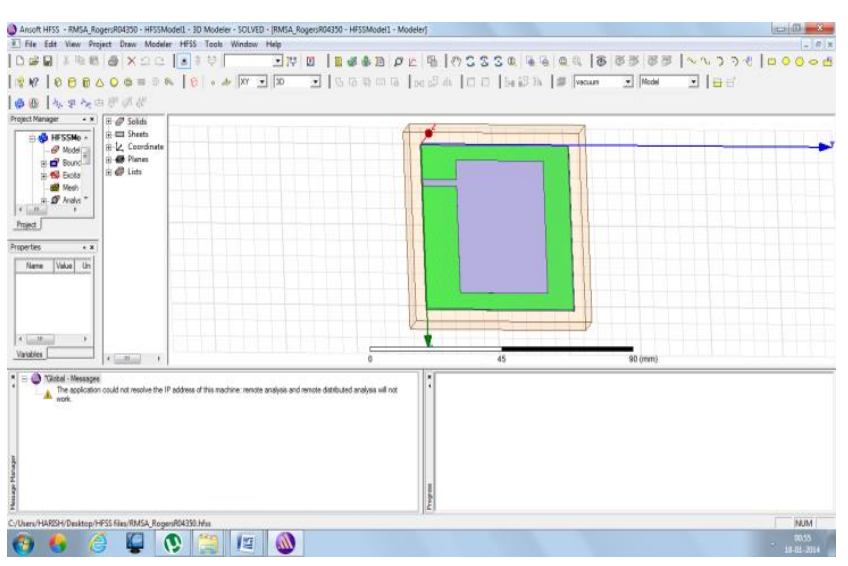

Figure 3 : RMSA Design of Rogers RO4350 for Microstrip Feed. 


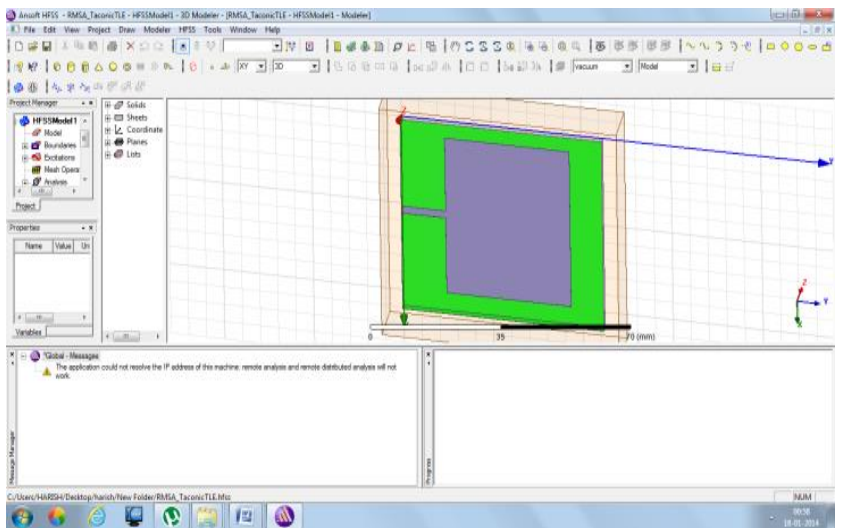

Figure 4 :RMSA Design of Taconic TLE for Microstrip feed

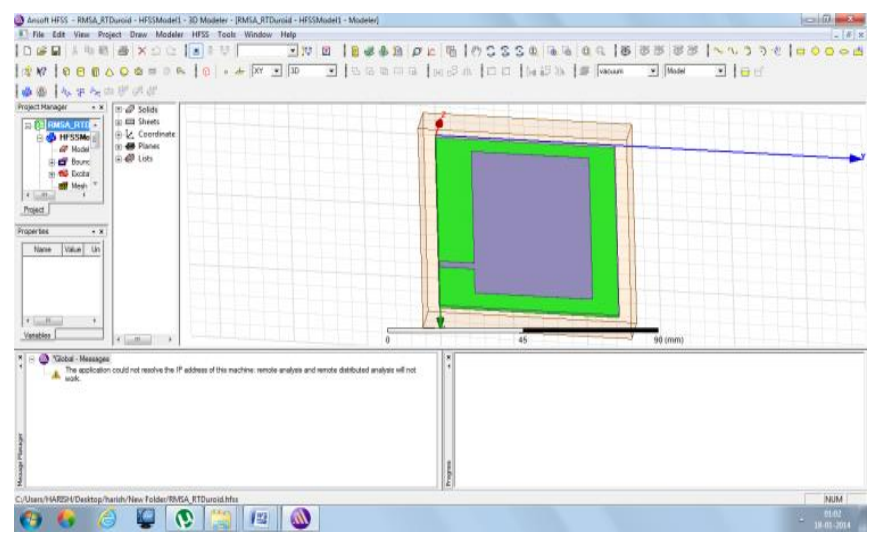

Figure 5 : RMSA Design of Rogers RT Duriod for Microstrip feed

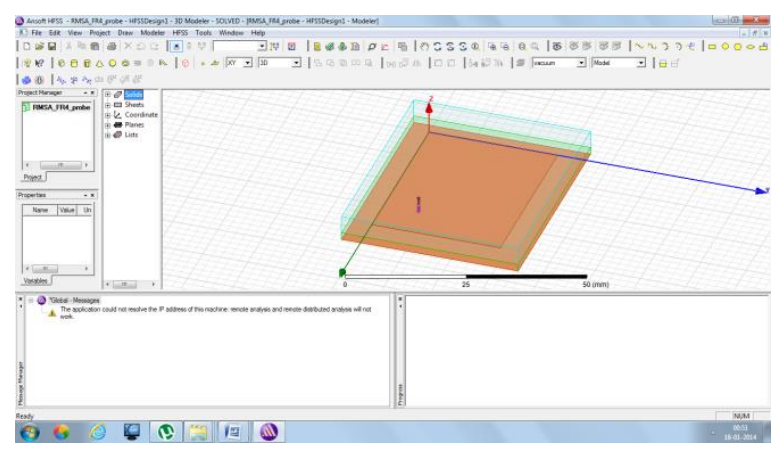

Figure 6 : RMSA Design of Rogers FR4 Probe feed

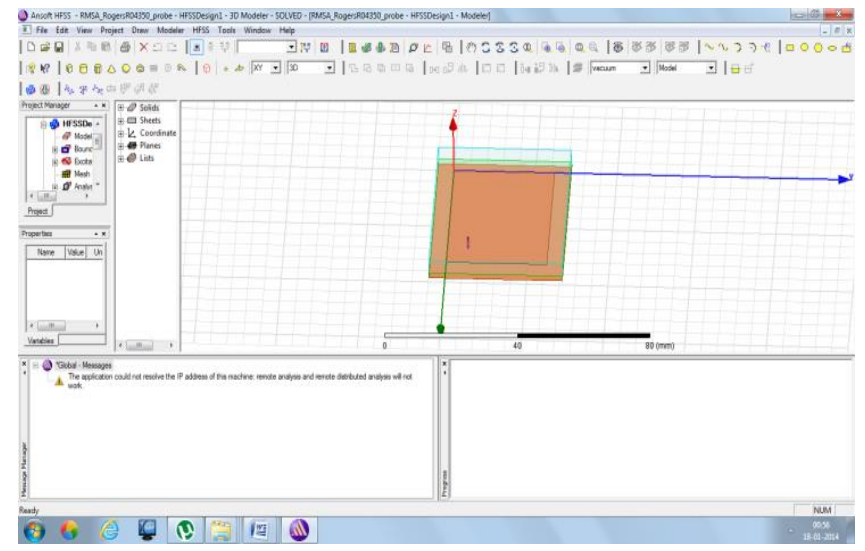

Figure 7 : RMSA Design of Rogers RO4350 Probe feed

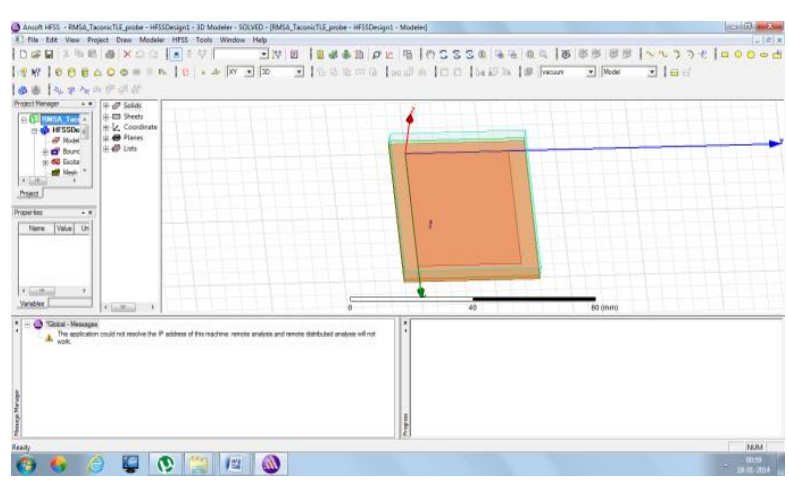

Figure 8: RMSA Design of Taconic TLE Probe feed

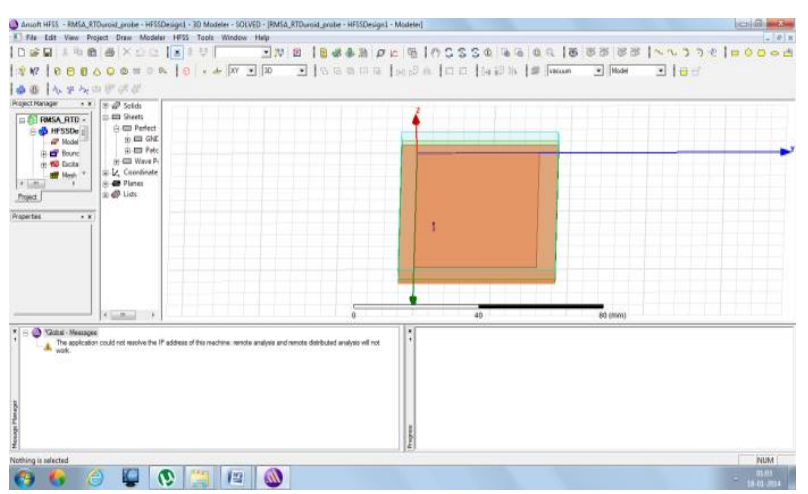

Figure 9 : RMSA Design of RT Duriod Probe feed 


\section{VII.SIMULATION RESULT}

\section{A. For Microtrip Feed.}

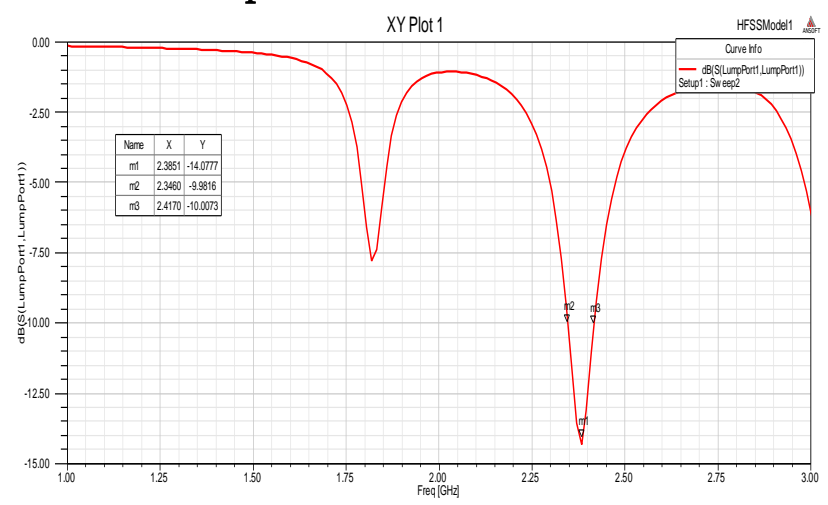

Figure 10: S11 graph of RMSA FR4

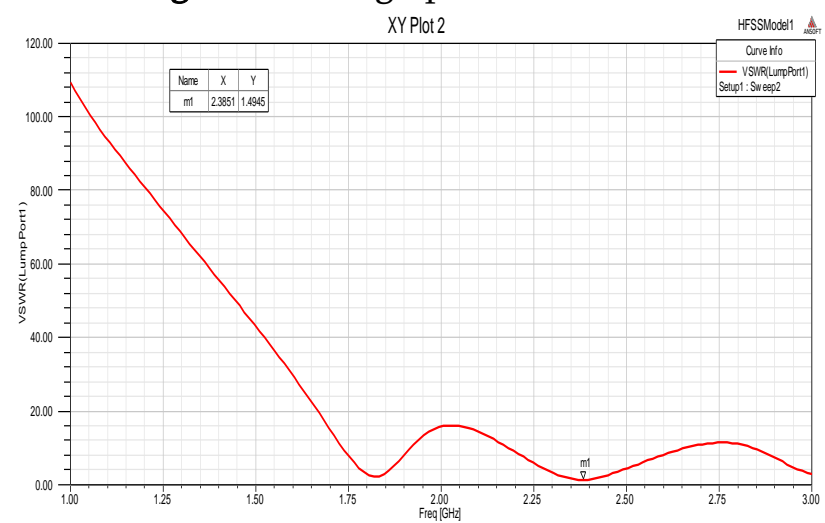

Figure 11: VSWR graph of RMSA FR4

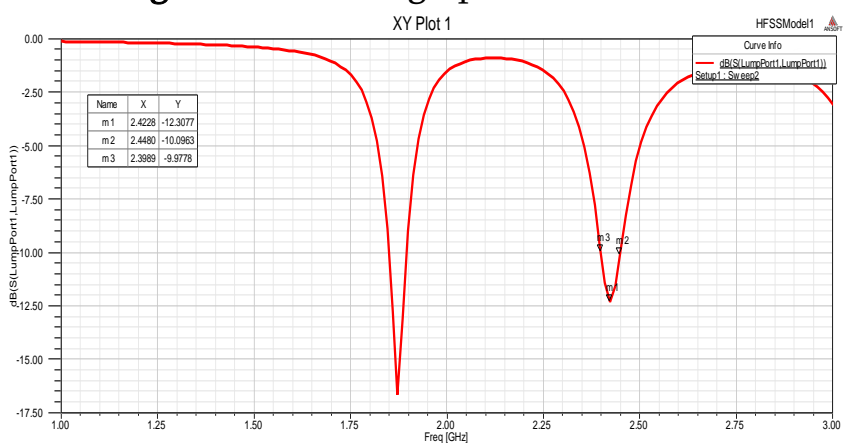

Figure 12: S11 graph of RMSA Rogers RO4350

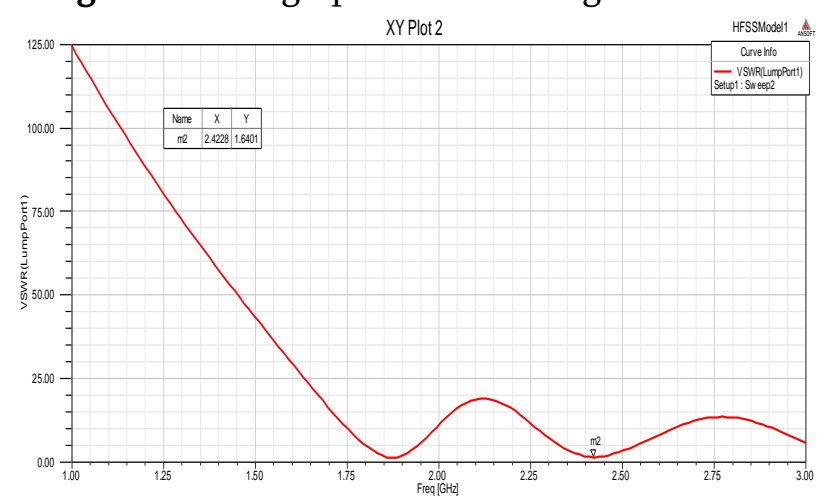

Figure 13: VSWR graph of RMSA Rogers RO4350

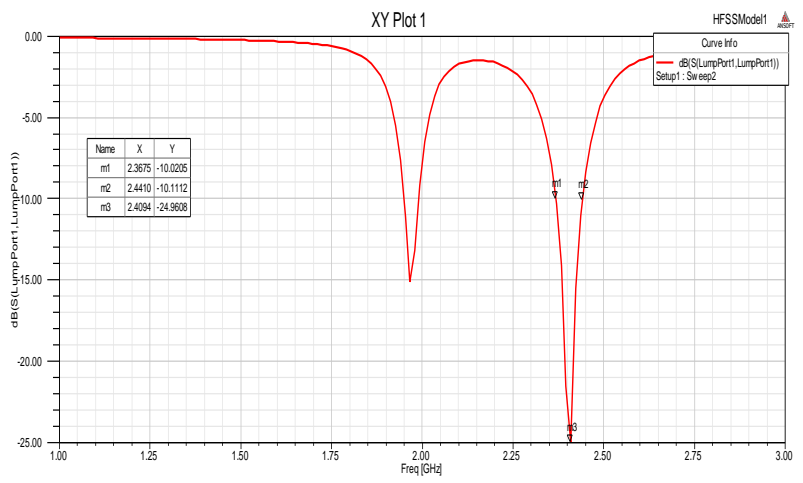

Figure 14: S11 graph of RMSA Teconic TLE

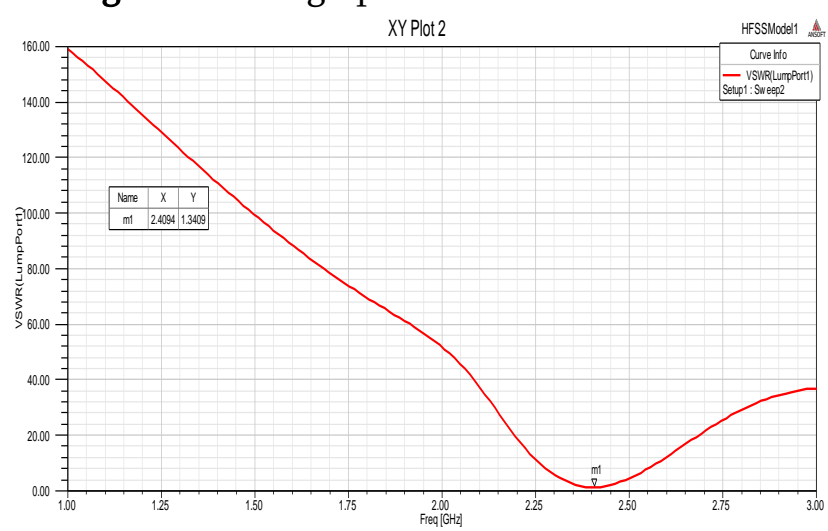

Figure 15: VSWR Graph of Taconic TLE

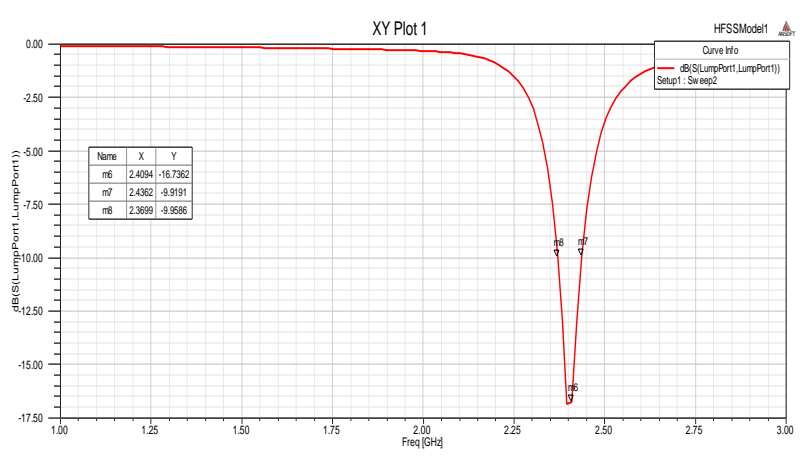

Figure 16: S11 graph of RMSA RT Duroid

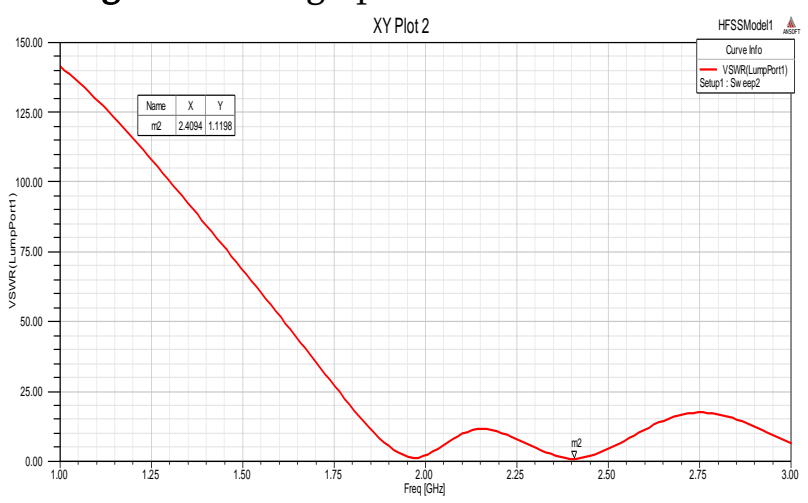

Figure 17: VSWR graph of RMSA RT Duroid 
B. Result of Microstrip Feed for Different Substrates at $2.4 \mathrm{GHz}$ frequency.

\begin{tabular}{|l|c|c|c|c|c|}
\hline Substrat & $\begin{array}{c}\text { Reson } \\
\text { ant } \\
\text { Freq(s } \\
\text { ) } \\
{[\mathrm{GHz}]}\end{array}$ & $\begin{array}{c}\text { VSW } \\
\mathbf{R}\end{array}$ & $\begin{array}{c}\text { BW } \\
(\mathrm{MH} \\
\mathbf{z})\end{array}$ & $\begin{array}{c}\text { Gai } \\
\mathbf{n} \\
(\mathrm{dB}\end{array}$ & $\begin{array}{c}\text { Impedanc } \\
\mathbf{e} \\
\mathbf{R + j X}\end{array}$ \\
\hline FR4 & 2.40 & 1.63 & 71 & 0.3 & $32.75+\mathrm{j} 9$. \\
& & 1 & & 30 & 54 \\
\hline Rogers & 2.40 & 1.91 & 49.1 & 1.7 & $34.96-$ \\
RO4350 & & 6 & & 32 & $\mathrm{j} 22.89$ \\
\hline Taconic & 2.40 & 1.34 & 66.3 & 2.8 & $37.29-$ \\
TLE & & 0 & & 74 & $\mathrm{j} 0.124$ \\
\hline RT & 2.40 & 1.19 & 73.5 & 3.3 & $44.79+\mathrm{j} 1$. \\
Duroid & & 8 & & 23 & 258 \\
5880 & & & & & \\
\hline
\end{tabular}

\section{Probe Feeding Result}



Figure 18: S11 graph of RMSA FR4

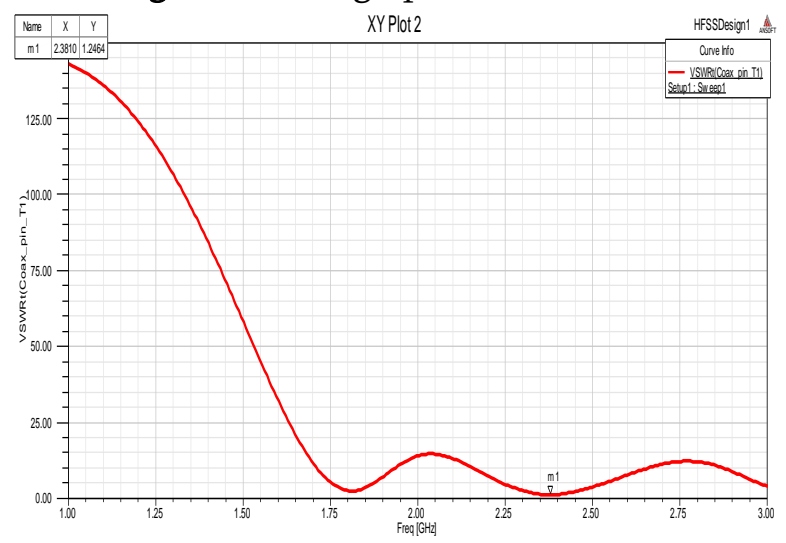

Figure 19: VSWR Graph of FR4

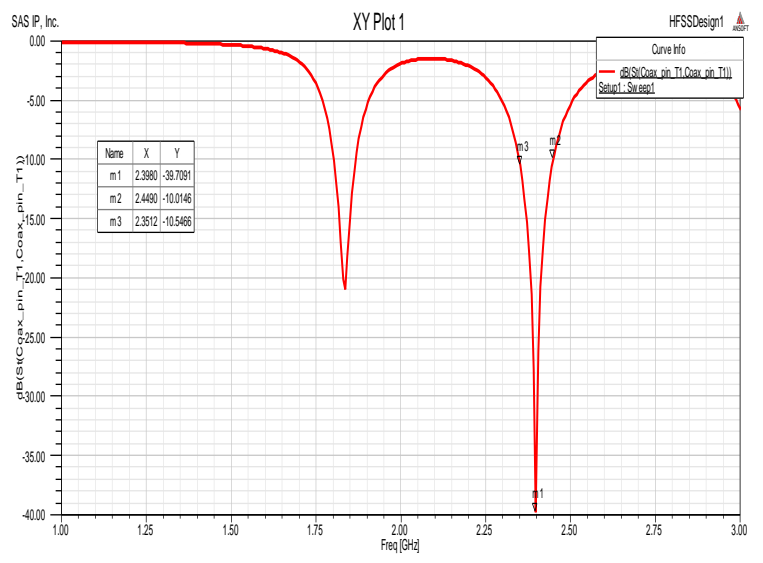

Figure 21: S11 graph of RMSA Rogers RO4350

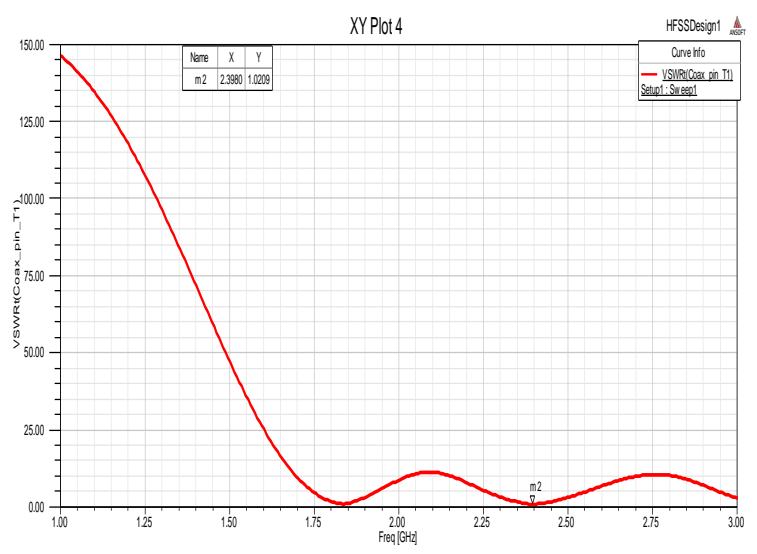

Figure 22: VSWR graph of RMSA Rogers RO4350

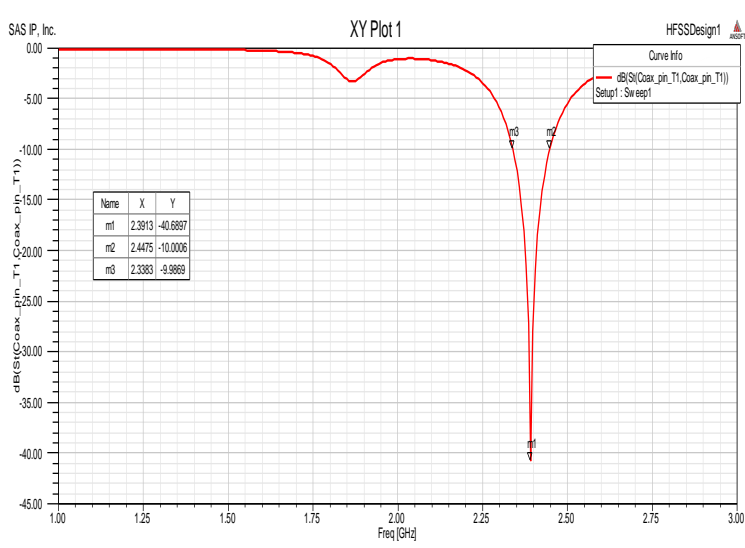

Figure 23: S11 graph of RMSA Taconic TLE 


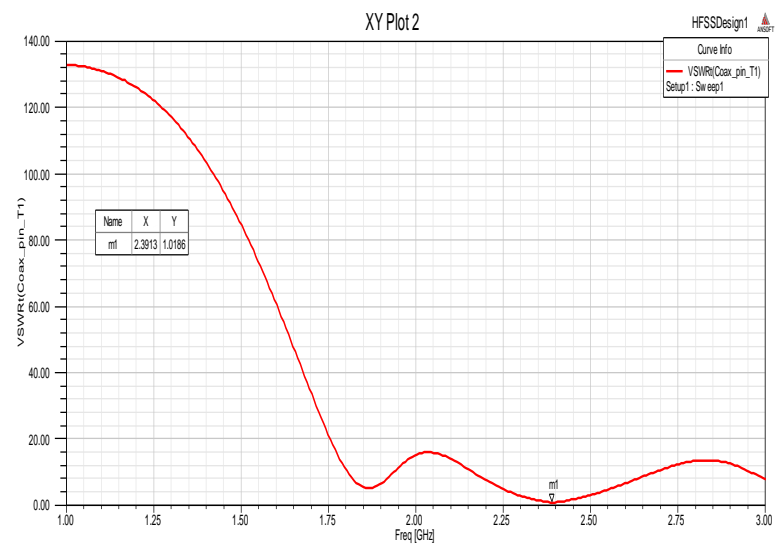

Figure 24: VSWR graph of RMSA Taconic TLE

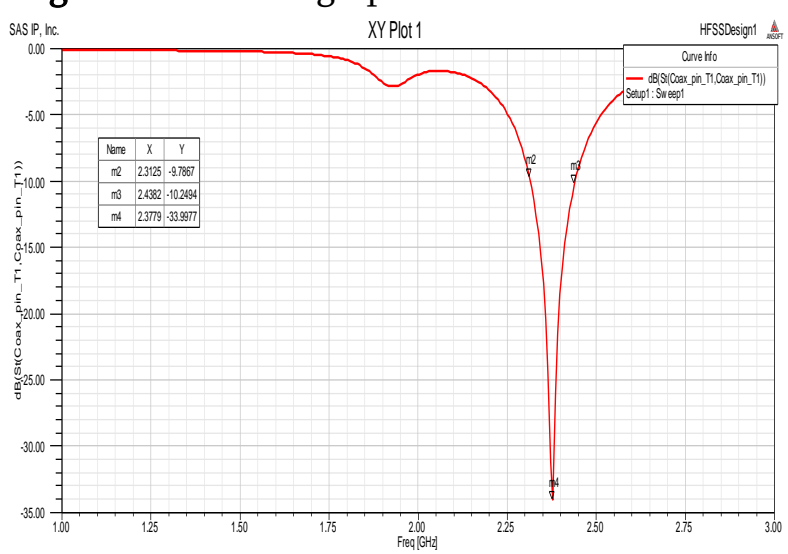

Figure 25: S11 graph of RMSA RT Duroid

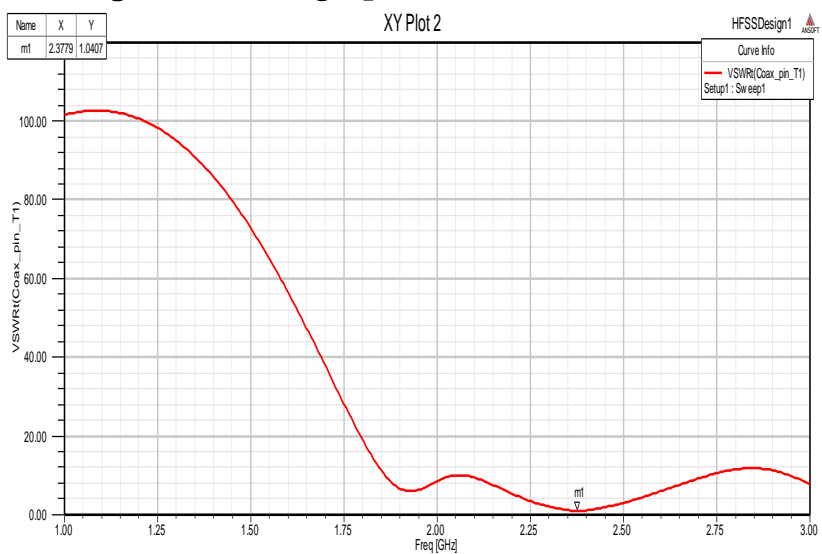

Figure 26: VSWR graph of RMSA RT Duroid

\section{Result of Probe Feed for Different Subtrates at 2.4 $\mathrm{GHz}$ frequency.}

\begin{tabular}{|c|c|c|c|c|c|}
\hline $\begin{array}{c}\text { Substrat } \\
\text { e }\end{array}$ & $\begin{array}{c}\text { Resona } \\
\text { nt } \\
\text { Freq(s) } \\
{[\mathrm{GHz}]}\end{array}$ & $\begin{array}{c}\text { VS } \\
\text { W } \\
\text { R }\end{array}$ & $\begin{array}{c}\text { BW } \\
(\mathrm{MHz})\end{array}$ & $\begin{array}{c}\text { Gain } \\
(\mathrm{dB})\end{array}$ & $\begin{array}{c}\text { Imped } \\
\text { ance } \\
\mathrm{R}+\mathrm{jX}\end{array}$ \\
\hline FR4_ep & 2.40 & 1.4 & 97.3 & 1.32 & $35.12-$ \\
\hline
\end{tabular}

\begin{tabular}{|l|c|c|c|c|c|}
\hline oxy & & 26 & & 1 & $\mathrm{j} 0.747$ \\
\hline Rogers & 2.40 & 1.0 & 97.8 & 1.58 & $49.61-$ \\
RO4350 & & 45 & & 0 & $\mathrm{j} 1.864$ \\
\hline Taconic & 2.40 & 1.1 & 109.2 & 1.87 & $46.64-$ \\
TLE & & 13 & & 0 & $\mathrm{j} 3.725$ \\
\hline RT & 2.40 & 1.2 & 125.7 & 2.03 & $39.56-$ \\
Duroid & & 94 & & 5 & $\mathrm{j} 4.761$ \\
5880 & & & & & \\
\hline
\end{tabular}

\section{CONCLUSION}

- Rogers RT Duroid 5880 is the best among the 4 substrates chosen as it has lowest loss tangent

- Rogers RT Duroid 5880 gives best result in comparison to all the 4 substrates both co-axial or microstrip feed.

- Probe/Co-axial feed is better than microstrip feed as a better match is achieved resulting in better BW and gain.

- However probe feed is difficult to fabricate as compared to microstrip feed

\section{REFERENCES}

[1]. Kashwan K R ,Rajeshkumar V, Gunasekaran T and Shankar Kumar K R, "Design and Characterization of Pin Fed Microstrip Patch Antennae", IEEE proceedings of FSKD'2011

[2]. Jagdish. M. Rathod, Member, IACSIT, IETE (I), IE (I), BES (I) ,"Comparative Study of Microstrip Patch Antenna for Wireless Communication Application", IJIMT, Vol. 1, No. 2, June 2010

[3]. Govardhani.Immadi, M.S.R.S Tejaswi, M.Venkata Narayana," Design of Coaxial fed Microstrip Patch Antenna for $2.4 \mathrm{GHz}$ BLUETOOTH Applications,Journal of Emerging Trends in Computing and Information Sciences VOL. 2, NO. 12, December 2011. 
[4]. P.J.Soh, M.K.A.Rahim, A.Asrokin, M.Z.A.Abdul Aziz, "Design, modeling and performance comparison of different feedingtechniques for a microstrip patch antenna", Journal technology in university technology Malaysia, 47(D) Dis. 2007 103-120.

[5]. C. A. Balanis, 1982, Antenna Engineering, 2nd ed., Willey.

[6]. Ahmed Fatthi Alsager Design and Analysis of Microstrip Patch Antenna Arrays thesis comprises 30 ECTS credits and is a compulsory part in the Master of Sciencewith a Major in Electrical Engineering Communication and Signal processing. Thesis No. 1/2011

\section{Cite this article as :}

Harish Langar, Atul Shire, "Comparative Study of Microstrip Patch Antenna for Different Feed Line and Different Substrate", International Journal of Scientific Research in Science and Technology (IJSRST), Online ISSN : 2395-602X, Print ISSN : 23956011, Volume 7 Issue 2, pp. 462-469, March-April 2020. Available at doi : https://doi.org/10.32628/IJSRST207277 Journal URL : http://ijsrst.com/IJSRST207277 